\title{
A pilot study of the effect of providing daily free fruit to primary-school children in Auckland, New Zealand
}

\author{
Pauline AL Ashfield-Watt ${ }^{1} *$, Elizabeth A Stewart ${ }^{1}$ and Judi A Scheffer ${ }^{2}$ \\ ${ }^{1}$ Institute of Food Nutrition and Human Health, Massey University, SH 16 Albany, North Shore Mail Centre, \\ Private Bag 902 104, Auckland, New Zealand: ${ }^{2}$ Institute of Information and Mathematical Sciences, Massey \\ University, Auckland, New Zealand
}

Submitted 9 January 2008: Accepted 2 May 2008: First published online 29 July 2008

\begin{abstract}
Objective: To determine the uptake of a free fruit provision to low-decile primaryschool children by quantitatively assessing changes in fruit intake.

Design: A randomised controlled trial using a paired, cluster randomisation.

Setting: Twenty low-decile primary schools (schools attended by the most deprived children) in Auckland, New Zealand.

Subjects: In total 2032 children, aged 7-11 years, provided data on at least one occasion.

Intervention: Ten pairs of low-decile primary schools matched by roll size and location were randomly allocated to control (no free fruit) or intervention (free fruit) for a school term. Dietary assessments using the $24 \mathrm{~h}$ recall methodology were made at baseline, on the last week of the intervention and 6 weeks postintervention.

Results: Fruit intakes in this cohort were lower than the national average with over $40 \%$ reporting no fruit intake at baseline and did not differ between groups. After the free fruit period the intervention group increased school fruit intakes by 0.39 pieces/school $\mathrm{d}$ from baseline $(P \leq 0 \cdot 001)$ and the proportion of children consuming no fruit reduced to $22 \%$. This increase, however, was not sustained and fruit intakes fell below baseline levels at 6 weeks post-intervention. Control subjects did not significantly alter their fruit intakes throughout the study.

Conclusions: Improving exposure and accessibility to fruits at school increases fruit intakes of low socio-economic group children, particularly those who do not normally eat fruit. The present pilot study demonstrates some possible negative effects of short-term free fruit interventions, but is informative for developing and evaluating sustained fruit intervention programmes.
\end{abstract}

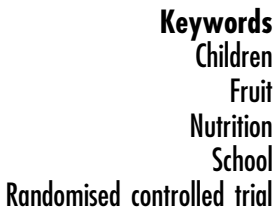

It is widely accepted that fruit and vegetables are important foods for maintaining health and preventing chronic diseases such as CVD and cancer ${ }^{(1)}$. Therefore, fruits and vegetables feature prominently in food-based dietary guidelines and in many national recommendations for healthy diets. Despite this, inadequate intakes have been reported in both adults and children ${ }^{(1,2)}$. The major barriers to adequate fruit and vegetable consumption have been researched extensively and include individual preferences, availability and access ${ }^{(3,4)}$.

Children are more likely to eat those foods they recognise and are familiar with ${ }^{(5,6)}$. Therefore, exposure of children to a range of fruits and vegetables through modification of their food environment may help establish and reinforce healthy food habits ${ }^{(7)}$. Food habits established in childhood track through to adulthood and adult diseases can be tracked back to childhood eating patterns ${ }^{(8-10)}$. Therefore, establishing healthy eating patterns early in life may be an important step in preventing later morbidity and premature mortality.

To date, most efforts to improve fruit and vegetable intakes in school children have involved multi-component interventions ${ }^{(11)}$. Only a few studies have reported stand-alone interventions designed to increase exposure to fruit and vegetables directly in young children ${ }^{(12-14)}$ and it is not known if their results are generalisable to New Zealand children. For practical and sensory reasons it has been suggested that it is easier to increase fruit than vegetable intakes ${ }^{(12,14)}$. Direct provision of either subsidised or free fruit to children within their usual environment substantially reduces or removes availability and access issues while simultaneously increasing exposure.

In 2003 the first ever New Zealand National Children's Nutrition Survey reported low fruit and vegetable intakes 
in New Zealand children, particularly those of low socioeconomic status and from certain ethnic groups (children with Maori and Pacific Island heritage) ${ }^{(15)}$. In response to this, as part of the 'Healthy Eating Healthy Action' Strategic Plan for Health ${ }^{(16,17)}$ and encouraged by the success of pilot interventions overseas in England ${ }^{(18)}$ and the $\mathrm{USA}^{(19,20)}$, the New Zealand Ministry of Health undertook a feasibility study to determine whether primary-school children from low socio-economic communities in the city of Auckland would increase their fruit consumption if it was provided free at school. Budgetary and time constraints affected the duration of the intervention, which was limited to providing free fruit on each school day over a single school term. The aim of the current study was to measure quantitatively the effect of the free fruit intervention using a validated dietary survey method.

\section{Subjects and methods}

\section{Recruitment and identification of schools}

Schools for the present study were selected from Auckland suburbs with a high level of economic deprivation. The majority of schools were in the area of South Auckland served by the Counties Manukau District Health Board. Forty-five per cent of children living here are classified as the most deprived in the country ${ }^{(21)}$. Decile 1 schools represent the $10 \%$ of schools with the greatest proportion of students from low socio-economic backgrounds. The majority of pupils attending these schools have a Maori or Pacific Island heritage.

\section{Study design}

For practical reasons and to avoid treatment contamination, a paired, cluster randomisation was employed. Ten pairs of decile 1 schools, matched for 2003 academic year roll size and geographic location, were selected. The decision to intervene in ten schools was pragmatic and influenced by the required sample size, the need to include a variety of different sized schools within the area, the need to accommodate logistic considerations and the funding available. Within each pair of schools one school was randomly allocated to receive free fruit (intervention) and the other to receive no free fruit (control). All children attending each intervention school received free fruit. There were no applicable fees to parents. Dietary intakes were assessed on three occasions, as explained below.

\section{Intervention}

A variety of export-quality, seasonal fruits were provided to the intervention schools during the first term of 2004 (10 weeks). Fruits included apples, pears, nashi pears (round, crisp, sweet pears grown in South-East Asia), oranges, plums and bananas. Quality control of fruit deliveries was coordinated by the national ' $5+$ a day' fruit and vegetables programme. Distribution of the fruits within schools was undertaken by the children under direction of a nominated teacher. Enough fruit was provided for all children to have at least one piece per school day. Due to the known cognitive limitations of younger children $^{(22)}$ and the age of children in whom the dietary assessment tool had been validated ${ }^{(23)}$, only 7-11-year-olds were included in the current evaluation.

\section{Dietary assessment method}

The 'Day in the Life Questionnaire' (DILQ) was chosen because it was easy and fun to complete and had demonstrated ability to detect changes in children's fruit intakes in a population with similar national estimates of fruit intake ${ }^{(15,23,24)}$. The questionnaire used a diet recall methodology which prompted children to record their activities and all foods eaten throughout the previous day (without specifically drawing their attention to fruit intakes): breakfast, on the way to school, morning break, lunch, after school, dinner and before bed. Demographic data were also collected. The questionnaire was administered in class (on any school day except Monday) by the teachers, who had been provided with detailed instructions on the completion of the questionnaire. Hence, fruit intakes reported herein are the number of pieces per school day (pieces/school d).

\section{Data collection}

Baseline dietary data were collected one week prior to commencement of the free fruit intervention (A1). The second assessment (A2) was undertaken during the last week of the intervention period and the third assessment (A3) was undertaken 6 weeks post-intervention.

\section{Data processing}

Fruit intakes were determined from the DILQ by a trained data coder. The number of whole pieces of fruit consumed by each child on the recording day was determined. A handful of dried fruit or a serving of chopped/ small fruit was coded as a single piece. Fruit juice consumption was not included in the estimates of fruit intake. Fruit intakes were summarised in two ways: (i) total fruit intake summarised all fruit intake throughout the day; and (ii) fruit at school summarised fruit eaten at morning break and lunch times only, regardless of source.

In some instances the children's descriptions of foods were unintelligible. This yielded missing values for total fruit intakes and/or fruit at school intakes. There were more missing values for total fruit intakes than for fruit at school intakes because the former included the main evening meal, which was often poorly recorded. The fruit at school intake variable better indicates the uptake of the free fruit while the total fruit intake variable indicates the effect of the free fruit on overall school-day intakes. Figure 1 shows the number of children who participated at each assessment and the number of children who provided useful intake data. A post hoc examination of 
Total number of eligible subjects
(provided data at any assessment)

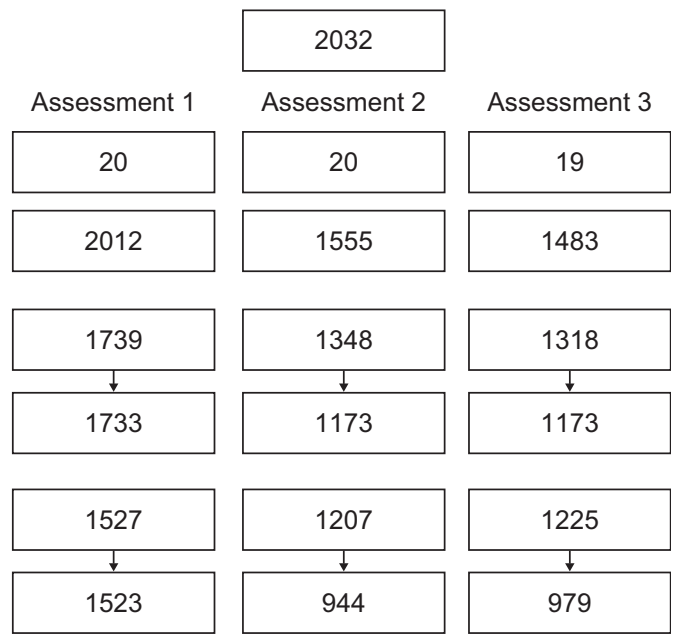

Fig. 1 Flow chart showing the number of subjects who participated at each assessment: pilot study on the effect of providing daily free fruit to primary-school children in Auckland, New Zealand. †Number of children included in analyses after adjustment for gender (133 missing values), baseline intake (at assessment 2 and assessment 3), intervention and school pair (with nested intervention); łfewer eligible responses were available for total fruit intakes because this summary variable included the evening meal, which was poorly recorded by subjects

missing values within the fruit intake data indicated that the only factor associated with missing values at all assessments was age (all $P<0 \cdot 05$ ). Younger children tended to have more missing data than older ages, but this trend was not significant at any assessment.

\section{Statistical power}

A conservative estimate of only $20 \%$ uptake of the free fruit intervention was used to determine sample size. A change of this magnitude would be detected at the $5 \%$ significance level with $80 \%$ power in a sample of 348 intervention and 348 control subjects, based on published New Zealand intake data ${ }^{(25)}$. Post hoc, we observed that fruit intakes in this cohort were more dispersed than in the reference group. The design effect, calculated by the method of Kish, was found to be $0 \cdot 82^{(26)}$.

\section{Data analysis}

Data were analysed using the Statistical Package for the Social Sciences statistical software package versions $12 \cdot 0$ and 14.0 (SPSS Inc., Chicago, IL, USA). All $P$ values are two-sided and $5 \%$ level of significance was used. Associations between categorical variables were assessed using the $\chi^{2}$ test with nominal by interval directional measures. Unadjusted data were analysed using nonparametric tests as appropriate.

Main study effects were analysed using the general linear mixed model (GLMM) procedure with a random intercept for school pair, as appropriate for a paired, clustered randomisation ${ }^{(14,27)}$. Initially saturated models were fitted with interaction, but in the interest of parsimony redundant variables (ethnicity, age and interactions) were removed from subsequent models. Final models included intervention, school pair (with nested intervention), gender and baseline intake estimate. Skewed intake variables were transformed using the natural logarithm to produce approximately normal distributions. Fruit intake data presented in tables and text are the average number of pieces of fruit consumed per school day. Unless stated otherwise, these are adjusted intake estimates (geometric mean (sE)) derived from GLMM.

For investigation of change in intake patterns between time points, fruit intake data were categorised as follows: 0 pieces/school d, 1 piece/school d and $\geq 2$ pieces/school d. Transition of intakes between these dietary intake groups was investigated using ordinal regression (polytomous universal model, PLUM; SPSS 12.0) to produce event probabilities for observed intakes at $\mathrm{A} 2$ and $\mathrm{A} 3^{(28)}$.

\section{Etbical approval}

Ethical approval was obtained from Massey University Animal and Human Ethics Committee and was contingent upon written approval from the Board of Trustees of all schools, consultation with Maori and Pacific peoples' representatives, and informed, written parental and child consent.

\section{Results}

All data presented herein relate to children who fulfilled the study eligibility criteria and provided data at one or more assessments, in total 2032 pupils (1035 intervention and 997 control children). This represents $55 \%$ of $\geq 7$ year-old children enrolled at the participating schools during the 2004 academic year (personal communication, Ministry of Education, 2004). The main reason for nonparticipation was lack of parental consent. The reason for 
this is unknown. Of those children who participated, 56\% returned questionnaires at all assessments, 31\% at two assessments and $13 \%$ at only one assessment. Compliance with questionnaire completion was significantly associated with intervention grouping $(P<0 \cdot 001)$, but not with age, gender or ethnicity. More intervention group subjects (61\%) than controls (51\%) returned questionnaires at all assessments, with one control school not returning any A3 questionnaires (sixty-two study participants).

\section{Baseline data}

Population characteristics

The control and intervention groups were balanced for gender and mean age. By chance, there was some variation in the age distribution of the two groups, but overall proportions of younger (7-8-year-olds) and older ( $\geq 9$-year-olds) children were similar. The distribution of ethnic groupings in both groups reflected the known ethnic distribution within low socio-economic groups in Auckland. Pacific people and Maori made up 81\% of each study group (Table 1). There was greater variation in proportions of other ethnicities between the treatment groups, but the overall numbers involved were small compared with the major ethnic groups represented.

Factors affecting fruit intakes at baseline (A1)

The control and intervention groups were balanced at baseline in terms of total and school fruit intake estimates (Table 2). Fruit intakes were higher in girls than in boys (total fruit: girls, 0.99 (se 0.02) pieces/school d; boys, 0.74

Table 1 Characteristics of control and intervention group subjects at baseline: pilot study on the effect of providing daily free fruit to primaryschool children in Auckland, New Zealand

\begin{tabular}{|c|c|c|c|c|c|}
\hline \multirow[b]{2}{*}{ Demographic characteristic } & \multirow[b]{2}{*}{ Subgroup } & \multicolumn{2}{|c|}{ Control $^{*}$} & \multicolumn{2}{|c|}{ Intervention* } \\
\hline & & $n$ & $\%$ & $n$ & $\%$ \\
\hline \multirow[t]{2}{*}{ Gender } & Males & 446 & $50 \cdot 1$ & 502 & $49 \cdot 7$ \\
\hline & Females & 444 & $49 \cdot 9$ & 508 & $50 \cdot 3$ \\
\hline \multirow[t]{5}{*}{ Age distribution (years) $\dagger$} & 7 & 137 & $18 \cdot 3$ & 123 & $21 \cdot 0$ \\
\hline & 8 & 170 & $22 \cdot 8$ & 204 & $27 \cdot 9$ \\
\hline & 9 & 176 & $23 \cdot 6$ & 196 & $26 \cdot 8$ \\
\hline & 10 & 202 & $27 \cdot 0$ & 196 & $26 \cdot 8$ \\
\hline & $11+$ & 62 & $8 \cdot 3$ & 11 & $1 \cdot 5$ \\
\hline \multirow[t]{5}{*}{ Ethnicitył } & Asian & 11 & $1 \cdot 2$ & 21 & $2 \cdot 1$ \\
\hline & European & 31 & $3 \cdot 5$ & 56 & $5 \cdot 5$ \\
\hline & New Zealand Maori & 204 & $22 \cdot 8$ & 236 & $23 \cdot 3$ \\
\hline & Pacific People & 512 & $57 \cdot 3$ & 586 & $57 \cdot 8$ \\
\hline & Mixed/Other & 135 & $15 \cdot 1$ & 114 & $11 \cdot 3$ \\
\hline \multirow[t]{3}{*}{ Total fruit intake (pieces/school d) } & 0 & 280 & $42 \cdot 6$ & 373 & $42 \cdot 9$ \\
\hline & 1 & 156 & $23 \cdot 7$ & 210 & $24 \cdot 2$ \\
\hline & $>2$ & 222 & $33 \cdot 7$ & 286 & 32.9 \\
\hline
\end{tabular}

* Mean age of control and intervention groups was 8.8 (SD 1.2) years and $8 \cdot 7$ (SD 1.1) years, respectively.

tSignificantly different distribution between groups $\left(\chi^{2}\right.$ test): $P=0 \cdot 001$.

$\ddagger$ Significantly different distribution between groups $\left(\chi^{2}\right.$ test): $P \leq 0.05$.

Table 2 Fruit intakes at all assessments: pilot study on the effect of providing daily free fruit to primary-school children in Auckland, New Zealand

\begin{tabular}{|c|c|c|c|c|c|c|c|c|c|c|c|c|c|}
\hline \multirow[b]{3}{*}{ Time point } & \multirow[b]{3}{*}{ Location } & \multicolumn{6}{|c|}{ Control } & \multicolumn{6}{|c|}{ Intervention } \\
\hline & & \multicolumn{3}{|c|}{ Crude intakes } & \multicolumn{3}{|c|}{ Adjusted intakes* } & \multicolumn{3}{|c|}{ Crude intakes } & \multicolumn{3}{|c|}{ Adjusted intakes* } \\
\hline & & $n$ & Mean & SE & $n$ & Mean & SE & $n$ & Mean & SE & $n$ & Mean & SE \\
\hline \multicolumn{14}{|l|}{ Assessment 1} \\
\hline Fruit intaket & $\begin{array}{l}\text { Total } \\
\text { At school }\end{array}$ & $\begin{array}{l}658 \\
784\end{array}$ & $\begin{array}{l}1 \cdot 24 \\
0 \cdot 67\end{array}$ & $\begin{array}{l}0.06 \\
0.03\end{array}$ & $\begin{array}{l}656 \\
781\end{array}$ & $\begin{array}{l}0.86 \\
0.54\end{array}$ & $\begin{array}{l}0.03 \\
0.02\end{array}$ & $\begin{array}{l}869 \\
955\end{array}$ & $\begin{array}{l}1 \cdot 20 \\
0 \cdot 67\end{array}$ & $\begin{array}{l}0.05 \\
0.03\end{array}$ & $\begin{array}{l}867 \\
952\end{array}$ & $\begin{array}{l}0.85 \\
0.54\end{array}$ & $\begin{array}{l}0.02 \\
0.02\end{array}$ \\
\hline Assessment 2 & & & & & & & & & & & & & \\
\hline Fruit intake & 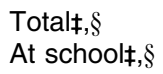 & $\begin{array}{l}562 \\
610\end{array}$ & $\begin{array}{l}1 \cdot 22 \\
0 \cdot 72\end{array}$ & $\begin{array}{l}0.06 \\
0.04\end{array}$ & $\begin{array}{l}381 \\
486\end{array}$ & $\begin{array}{l}0.92 \\
0.50\end{array}$ & $\begin{array}{l}0.04 \\
0.03\end{array}$ & $\begin{array}{l}638 \\
738\end{array}$ & $\begin{array}{l}1 \cdot 59 \\
1 \cdot 15\end{array}$ & $\begin{array}{l}0.06 \\
0.04\end{array}$ & $\begin{array}{l}563 \\
687\end{array}$ & $\begin{array}{l}1.22 \\
0.93\end{array}$ & $\begin{array}{l}0.03 \\
0.02\end{array}$ \\
\hline Assessment 3 & & & & & & & & & & & & & \\
\hline Fruit intake & 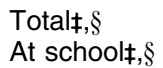 & $\begin{array}{l}596 \\
647\end{array}$ & $\begin{array}{l}1 \cdot 21 \\
0.75\end{array}$ & $\begin{array}{l}0.07 \\
0.05\end{array}$ & $\begin{array}{l}438 \\
550\end{array}$ & $\begin{array}{l}0.96 \\
0.52\end{array}$ & $\begin{array}{l}0.04 \\
0.03\end{array}$ & $\begin{array}{l}629 \\
671\end{array}$ & $\begin{array}{l}0.93 \\
0.55\end{array}$ & $\begin{array}{l}0.05 \\
0.03\end{array}$ & $\begin{array}{l}541 \\
623\end{array}$ & $\begin{array}{l}0.61 \\
0.37\end{array}$ & $\begin{array}{l}0.03 \\
0.02\end{array}$ \\
\hline
\end{tabular}

*Estimates are geometric means from general linear mixed models (GLMM) adjusted for school pair (with nested intervention) and gender. Follow-up models are also adjusted for baseline intakes.

†Fruit intake units are pieces/school d.

¥Significant difference compared with assessment 1: $P \leq 0.002$.

§Significant difference between groups (Mann-Whitney $U$ test): $P \leq 0 \cdot 01$. 
Table 3 Event probabilities* for school fruit intake grouping at follow-up assessments: pilot study on the effect of providing daily free fruit to primary-school children in Auckland, New Zealand

\begin{tabular}{|c|c|c|c|c|c|c|}
\hline \multirow[b]{2}{*}{ Assessment 1 intake (pieces/school d) } & \multirow[b]{2}{*}{ Treatment group } & \multirow[b]{2}{*}{$n$} & \multicolumn{3}{|c|}{ Assessment 2 intake (pieces/school d) } & \multirow[b]{2}{*}{$P$} \\
\hline & & & 0 & 1 & $\geq 2$ & \\
\hline \multirow[t]{2}{*}{0} & Control & 251 & 0.68 & $0 \cdot 22$ & 0.09 & $<0.001$ \\
\hline & Intervention & 363 & 0.36 & $0 \cdot 41$ & 0.23 & \\
\hline \multirow[t]{2}{*}{1} & Control & 120 & 0.42 & $0 \cdot 36$ & 0.22 & 0.001 \\
\hline & Intervention & 165 & $0 \cdot 19$ & 0.43 & 0.38 & \\
\hline \multirow[t]{3}{*}{$\geq 2$} & Control & 115 & 0.31 & 0.38 & 0.31 & 0.001 \\
\hline & Intervention & 159 & $0 \cdot 15$ & $0 \cdot 40$ & $0 \cdot 45$ & \\
\hline & & & \multicolumn{3}{|c|}{ Assessment 3 intake (pieces/school d) } & \\
\hline \multicolumn{3}{|l|}{ Assessment 2 intake (pieces/school d) } & 0 & 1 & $\geq 2$ & \\
\hline \multirow[t]{2}{*}{0} & Control & 225 & 0.67 & $0 \cdot 21$ & $0 \cdot 12$ & 0.20 \\
\hline & Intervention & 137 & 0.74 & $0 \cdot 17$ & 0.09 & \\
\hline \multirow[t]{2}{*}{1} & Control & 128 & 0.45 & $0 \cdot 33$ & $0 \cdot 22$ & 0.001 \\
\hline & Intervention & 217 & 0.62 & $0 \cdot 24$ & $0 \cdot 14$ & \\
\hline \multirow[t]{2}{*}{$\geq 2 \dagger$} & Control & 90 & $0 \cdot 31$ & $0 \cdot 25$ & 0.44 & $<0.001$ \\
\hline & Intervention & 168 & 0.56 & $0 \cdot 27$ & $0 \cdot 17$ & \\
\hline
\end{tabular}

*Event probabilities derived from polytomous universal models using negative log-log link function.

+Uses complementary log-log link function.

(se 0.02) pieces/school d; $P \leq 0 \cdot 001$ ), but were not significantly associated with either ethnicity or age. Over $40 \%$ of children in both groups ate no fruit at A1 (Table 1).

\section{Effect of intervention on fruit intakes at A2}

At A2 fruit at school intakes in the intervention group had increased by 0.39 pieces/school $\mathrm{d}$ and were significantly greater than intakes within the control group, which remained unchanged from baseline $(P<0 \cdot 001)$. This was largely achieved by a reduction of almost $50 \%$ in the proportion of intervention group children who ate no fruit compared with A1. Girls still had higher intakes than boys (total fruit: girls, 1.45 (se 0.04) pieces/school d; boys, 1.00 (SE 0.04) pieces/school d; $P \leq 0.001$ ), but there was no evidence of an interaction between intervention and gender.

\section{Transition of intakes between $A 1$ and $A 2$}

Further analyses of change in fruit at school intakes were performed using data from subjects who completed the DILQ at both A1 and A2 (controls, $n$ 486; intervention, $n 687)$. These analyses used grouped frequency data $(0,1$ or $\geq 2$ pieces/school d). Of the children who ate no fruit at baseline, the proportions eating 0,1 or $\geq 2$ pieces of fruit at school per day at A2 were significantly different between the control and intervention groups $(P<0 \cdot 001$; PLUM). Sixty-eight per cent of control group subjects who had eaten no fruit at school at baseline continued to eat no fruit at school at A2 compared with only 36\% of intervention group subjects. Of the remaining 64\% of intervention group subjects who had eaten no fruit at baseline, approximately two-thirds increased school fruit intake to 1 piece/school $\mathrm{d}$ and a third had increased to $\geq 2$ pieces/school d at A2 $(P<0 \cdot 001)$.

Intervention group children who had eaten fruit at school at baseline ( 1 or $\geq 2$ pieces/school d) were also more likely to continue eating or increase school fruit intake than control group children (both $P<0 \cdot 001$ ). Event probabilities for A2 intakes stratified according to A1 intakes are presented in Table 3. Overall, 43\% of intervention group subjects who provided data at A1 and A2 increased fruit at school intakes by at least 1 piece/ school d. Nineteen per cent of intervention group subjects were resistant to eating fruit as reflected by zero intakes at both time points.

\section{Effect of intervention on fruit intakes at A3}

Fruit intakes in the control group were unaltered at A3 compared with either A1 or A2 estimates. Total fruit and fruit at school intakes in the intervention group, however, fell significantly compared with A2 and were lower than intakes observed in the control group at A3 $(P \leq 0 \cdot 002$; Table 2).

\section{Transition of intakes from $A 2$ to $A 3$}

Intervention group children who had consumed 1 or $\geq 2$ pieces fruit/school d at A2 were more likely to be eating no fruit at A3 than control group subjects $(P=0 \cdot 001$ and $P<0 \cdot 001$, respectively; lower part of Table 3 ). Overall $53 \%$ of these subjects had reduced their intakes at A3 compared with A2, with approximately equal proportions reducing from the 1 pieces/school $\mathrm{d}$ and $\geq 2$ pieces/ school d categories.

\section{Transition of intakes from A1 to A2 to A3 (intervention group)}

Of the 490 subjects in the intervention group who provided data at all three time points, 9\% subjects had increased fruit at school intakes from baseline at A2 and maintained their A2 intakes through to A3 (grouped frequency data). Thirty-two per cent of subjects had 
increased fruit at school intakes during the free fruit intervention and then reduced their intakes at A3. Five per cent of subjects maintained their fruit at school intakes at their baseline grouping level and 13\% ate no fruit at any time point. The variations in fruit intakes over the three assessments observed in other subjects were not consistent with any obvious pattern.

\section{Discussion}

The present study of over 2000 Auckland children has shown that fruit intakes of children attending low-decile schools are below national estimates ${ }^{(15)}$. At baseline, over $40 \%$ of children reported eating no fruit compared with $23 \%$ of the same age group reported in the national survey. Providing free fruit at school has achieved a $50 \%$ reduction in fruit abstinence and a significant increase in fruit intakes overall, indicating that the fruit eating behaviours of these children are modifiable. Age and ethnic groupings did not significantly influence children's uptake of the free fruit. The relative homogeneity of the group of low-decile schoolchildren may explain why these predictors of intake differ from those consistently reported elsewhere ${ }^{(29)}$. Importantly, the present study suggests that for children of low socio-economic status, a single national approach for increasing fruit intakes may be effective.

The change in fruit intakes in the present study $(0 \cdot 4$ pieces/school d) is consistent with those reported in Danish $(0.4$ pieces/d), Norwegian $(0.7$ pieces $/ \mathrm{d})$ and English $(0.4$ pieces/d) school fruit/fruit and vegetable intervention studies ${ }^{(12,14,18)}$. However, only crude comparisons can be made, given the methodological differences between studies. A change of the magnitude observed in these studies suggests that either uptake of the fruits was less than $100 \%$ or the effect of the intervention on total fruit intakes was not additive. The good uptake of fruit reported by teachers, combined with the small reported wastage of produce, suggests that the latter may be true here (data not shown).

It is possible that for some subjects the free fruit simply displaced baseline fruit intakes. Two forms of displacement have been previously suggested. Eriksen et al. observed that Danish children who received fruit at school reduced their intakes of fruit outside school hours $^{(12)}$. A similar observation was made in the UK study and it was also suggested that the free fruit was substituted for fruit previously available at school $^{(30)}$. There was no evidence in the current study for displacement of the former type. At A2 fruit intakes at school had increased significantly, but without any change in the fruit intakes outside school. The importance of this is twofold: (i) it eliminates the possibility that the free school fruit displaced fruit that would normally have been eaten at home; and (ii) it suggests that the intervention did not encourage children to eat more fruit outside school.

The extent of displacement of fruit that would normally have been eaten at school is more difficult to assess and may have occurred in children who maintained, increased or even decreased their fruit intakes during the school day. The extent of displacement here cannot be accurately determined from the available data. Of the $43 \%$ of subjects who increased their fruit intakes only $9 \%$ had reported eating any fruit at baseline, indicating that the majority of children who increased their fruit intakes did not substitute one source of fruit for another. A crude estimate of displacement based on the observed fruit eating patterns suggests that displacement may have occurred in a maximum of $38 \%$ of children. Displacement not only masks the true effectiveness of an intervention by reducing the likelihood of a demonstrable increase in intakes, but also potentially replaces one source of fruit with another, perhaps less sustainable, source. Additionally, it reduces the possibility that the extra fruit provided will achieve the major goal of replacing nutrient-poor, energydense snacks in the children's diets. Therefore, this is an important issue to monitor and assess in future studies.

The reasons for a lack of uptake in approximately $20 \%$ children at A2 are unclear. Children's fruit intakes are influenced by food neophobia, availability/accessibility and innate preferences ${ }^{(31,32)}$. Food neophobia (the fear of new foods) has been significantly and negatively associated with children's intakes of fruit, vegetables and meats $^{(31)}$. Food neophobia and 'pickiness' can be overcome by repeated exposure to new foods ${ }^{(4,5,33-35)}$. Provision of a variety of high-quality fruits for 10 weeks in the present study removed availability and accessibility issues and would be expected to improve fruit intake behaviour through repeated exposure. Despite this, individual food preferences and other factors such as time, hunger and availability of other foods are likely to have affected intakes regardless of the success of the programme.

A disturbing outcome has been the rapidity and magnitude of the reduction in fruit intakes post-intervention. This suggests that although the children enjoyed eating the fruit when it was available, the intervention had little effect on children's wider dietary patterns and the observed improvements were transient. A reduction in fruit intakes was also reported in those children who moved out of the designated free fruit age range of a UK free school fruit study, casting doubt on the long-term benefits of shortduration, stand-alone, free fruit interventions ${ }^{(36,37)}$. In the current study, 53\% children who had eaten fruit at school at $\mathrm{A} 2$ reduced or, in most cases, had stopped eating fruit at school six weeks post-intervention. This outcome is of concern because it suggests that brief interventions, while showing short-term benefits, do not overcome the social and economic barriers which prevent fruit consumption in the first place and may, in fact, encourage dependence on the free provision. 
It has recently been proposed that interventions to increase fruit and vegetable intakes should 'include strategies aimed at making these behaviours habitual ${ }^{(38)}$. In the current study, although the choice to eat free fruits was self-determined and the children were repeatedly presented with free fruit, the intervention period may have been too short for habituation to occur. Longer intervention studies such as the recently reported Norwegian free fruit and vegetable programme (one school year duration) demonstrate sustained effects on fruit and vegetable intakes one year post-intervention ${ }^{(39,40)}$. This suggests that interventions of longer duration may improve long-term dietary habits.

The strengths of the current study arise from the large number of participants, the selection of subjects from similar socio-economic backgrounds, the pairing of schools and the lack of selection bias in regard to receiving the free fruit (all children received free fruit with no applicable fees). Data on family background, including social characteristics such as educational level of parents, number in household and employment status, may be useful for more accurately characterising the socio-economic status of each intervention group and could be considered in future studies. A low response rate from this socio-economic stratum was predicted and over-sampling undertaken to overcome this. The demographic data collected suggest that participants were unlikely to be different from non-participants within each school. The observation of lower than average fruit and vegetable intakes in this group compared with the recent National Children's Nutrition Survey does not support the notion of healthy responder bias reported elsewhere ${ }^{(41)}$. Therefore, the results of the present study are generalisable to children from other low socio-economic communities.

A possible limitation of the study was the ability of this group of 7-11-year-old children to accurately report their dietary intake. We observed a significant association between age and missing fruit intake data, with a nonsignificant trend towards more missing values at younger ages. However, there was no evidence of age-associated questionnaire response bias suggesting that children of all ages were prepared to complete the questionnaires, but younger children may have needed more help. We endeavoured to administer the questionnaire in a similar fashion to the validation study ${ }^{(23)}$. However, for several reasons, including resource constraints and the need to minimise class disruption, the questionnaires were administered by the class teacher rather than a trained observer. This may have led to some loss of data and should be a key consideration in planning future studies. Parental involvement may have improved the quality of dietary data; however, the literature is equivocal on this point ${ }^{(42-44)}$ and the need for parental involvement may have reduced participation rates in this group given the observed poor response to provision of informed consents.
The distribution of fruit intakes within each treatment condition at baseline suggests that the two groups were not different with respect to their ability to recall fruit intakes. This is also supported by the lack of association between treatment group and missing fruit intake data, suggesting that the children's capabilities to report intakes were not different in the two groups. However, it is of concern that questionnaire response rates at each assessment were lower in the control group than in the intervention group. The free fruit may have motivated greater compliance with questionnaire completion within the intervention group. Careful consideration should be given to this issue in future evaluation studies to ensure that both teachers and children recognise the importance of their role as controls.

The present study has demonstrated that free fruit provision can significantly improve fruit intakes in children of low socio-economic status. A third of children who provided data at all three time points increased fruit intakes when free fruit was made available and reduced intakes once the intervention ceased. These 'would if they could' children are the ones likely to benefit most from free fruit provision. It is important that fruit interventions for these children are both sustained and supported by family and community activities.

\section{Acknowledgements}

Contributors: P.A.L.A.-W. was responsible for study design, coordination, data analyses and writing the manuscript. E.A.S. was involved in study design and contributed to writing the manuscript. J.A.S. carried out the statistical analyses and commented on interpretation of data.

Funding: The present evaluation study, including the free fruit provision, was funded by the New Zealand Ministry of Health.

Conflict of interest declaration: None.

Acknowledgements: We gratefully acknowledge United Fresh NZ (Inc.) who coordinated the sourcing and distribution of the free fruit; specifically Mrs Paula Dudley, the produce manager. We are indebted to the staff and pupils of the twenty schools who participated in the study and acknowledge the work of Ms Kristin Leaity (Registered Dietitian; data coding), Ms Amy Overington (data entry) and Dr Jeanne Lawless (manuscript review).

\section{References}

1. World Health Organization (2003) Diet, Nutrition and the Prevention of Chronic Diseases. Technical Report Series no. 916. Geneva: WHO.

2. Pomerleau J, Lock K, McKee M \& Altmann DR (2004) The challenge of measuring global fruit and vegetable intake. J Nutr 134, 1175-1180. 
3. Weber-Cullen K, Baranowski T, Owens E, Marsh T, Rittenberry L \& de Moor C (2003) Availability, accessibility and preferences for fruit, $100 \%$ fruit juice and vegetables influence children's dietary behaviour. Health Educ Behav 30, 615-626.

4. Wardle J, Cooke LJ, Gibson EL, Sapochnik M, Sheiham A \& Lawson M (2003) Increasing children's acceptance of vegetables; a randomized trial of parent-led exposure. Appetite 40, 155-162.

5. Wardle J, Herrera M-L, Cook LJ \& Gibson EL (2003) Modifying children's food preferences: the effects of exposure and reward on acceptance of an unfamiliar food. Eur J Clin Nutr 57, 341-348.

6. Cockroft JE, Durkin M, Masding C \& Cade JE (2005) Fruit and vegetable intakes in a sample of pre-school children participating in the 'Five for All' project in Bradford. Public Health Nutr 8, 861-869.

7. Brug J, de Vet E, de Nooijer J \& Verplanken B (2006) Predicting fruit consumption: cognitions, intention and habits. J Nutr Educ Behav 38, 73-81.

8. Lake AA, Mathers JC, Rugg-Gunn AJ \& Adamson AJ (2006) Longitudinal change in food habits between adolescence (11-12 years) and adulthood (32-33 years): the ASH30 Study. J Public Health 28, 10-16.

9. Mikkilä V, Räsänen L, Raitakari OT, Pietinen \& Viikair J (2005) Consistent dietary patterns identified from childhood to adulthood: the cardiovascular risk in young Finns study. Br J Nutr 93, 923-931.

10. Maynard M, Gunnell D, Emmett P, Frankel S \& Davey Smith G (2003) Fruit, vegetables and antioxidants in childhood and risk of adult cancer: the Boyd Orr cohort. $J$ Epidemiol Community Health 57, 218-225.

11. French SA \& Stables G (2003) Environmental interventions to promote vegetable and fruit consumption among youth in school settings. Prev Med 37, 593-610.

12. Eriksen K, Haraldsdóttir J, Pederson R \& Flyger HV (2003) Effect of a fruit and vegetable subscription in Danish schools. Public Health Nutr 6, 57-63.

13. French SA, Story M, Jeffery RW, Snyder P, Eisenberg M, Sidebottom A \& Murray D (1997) Pricing strategy to promote fruit and vegetable purchase in high school cafeterias. J Am Diet Assoc 97, 1008-1010.

14. Bere E, Veierod MB \& Klepp KI (2005) The Norwegian School Fruit Programme: evaluating paid vs no-cost subscriptions. Prev Med 41, 463-470.

15. Parnell W, Scragg R, Wilson N, Schaaf D \& Fitzgerald E (2003) NZ Food, NZ Children: Key Results of the 2002 National Children's Nutrition Survey. Wellington: Ministry of Health.

16. Ministry of Health (2003) Healthy Eating - Healthy Action: Oranga kai - Oranga pumau: A Background 2003. Wellington: Ministry of Health.

17. Ministry of Health (2003) Healthy Eating - Healthy Action: Oranga kai - Oranga pumau: Strategic Framework 2003. Wellington: Ministry of Health.

18. Teeman D, Blenkinsop S, Ransley J, Schagen S, Scott E \& White G (2004) Evaluation of the Big Lottery Fund's National School Fruit and Vegetable Scheme, p. 13. London: Big Lottery Fund.

19. Buzby JC, Guthrie JF \& Kantor LA (2003) Evaluation of the USDA Fruit and Vegetable Program: Report to Congress. Food Assistance and Nutrition Research Program, Food and Rural Economics Division, Economic Research Service. Washington, DC: US Department of Agriculture.

20. National Archives and Records Administration (2004) The Child Nutrition and WIC Reauthorization Act of 2004 (Public Law 108-265, s 2507/HR 3637 enacted June 30, 2004). http://www.gpoaccess.gov/plaws/108publ. html
21. Jackson G, Palmer C, Lindsay A \& Peace J (2001) Counties Manakau Health Profile. Manukau, New Zealand: Counties Manukau District Health Board.

22. Livingstone MBE, Robson PJ \& Wallace JMW (2004) Issues in dietary intake assessment of children and adolescents. Br J Nutr 92, Suppl. 2, S213-S222.

23. Edmunds LD \& Ziebland S (2002) Development and validation of the Day in the Life Questionnaire (DILQ) as a measure of fruit and vegetable questionnaire for 7-9 year olds. Health Educ Res 17, 211-220.

24. Gregory J, Lowe S \& Bates C (2000) National Diet and Nutrition Survey: Young People Aged 4-18 Years. vol. 1: Report of the Diet and Nutrition Survey. London: Office of National Statistics.

25. Watson P, Rush E, Wall C, O'Brien M, McDonald B, Stewart E, Sladden K, Chevenkov A \& Wright H (2003) Development and Pretesting of Methodologies for the Children's Nutrition Survey. report 3: Validation Report. Auckland: Institute of Food, Nutrition and Human Health, Massey University.

26. Kish L (1977) Survey sampling. Reprinted in Sampling Techniques, 3rd ed., p. 85 [WG Cochran, editor]. New York: Wiley.

27. Sashegyi AI, Brown KS \& Farrell PJ (2000) Application of a generalized random effects regression model for clustercorrelated longitudinal data to a school-based smoking prevention trial. Am J Epidemiol 152, 1192-1200.

28. McCullagh P (1980) Regression models for ordinal data (with discussion). J R Stat Soc B 42, 109-142.

29. Rasmussen M, Krolner R, Klepp K-I, Lytle L, Brug J, Bere E \& Due P (2006) Determinants of fruit and vegetable consumption among children and adolescents: a review of the literature. Part 1: quantitative studies. Int J Behav Nutr Phys Act 3, 22-40.

30. Teeman D, Blenkinsop S, Ransley J, Schagen S, Scott E \& White G (2004) Evaluation of the Big Lottery Fund's National School Fruit and Vegetable Scheme. Draft Second Report, p. 20. London: Big Lottery Fund.

31. Cooke L (2004) The development and modification of children's eating habits. Nutr Bull 29, 31-35.

32. Blanchette L \& Brug J (2005) Determinants of fruit and vegetable consumption among 6-12 year old children and effective interventions to increase consumption. J Hum Nutr Diet 18, 431-443.

33. Birch LL, McPhee L, Shoba BC, Pirok E \& Steinberg L (1987) What kind of exposure reduces children's food neophobia? Appetite 9, 171-178.

34. Cooke L, Carnell S \& Wardle J (2006) Food neophobia and mealtime food consumption in 4-5 year old children. Int J Behav Nutr Phys Act 3, 14-19.

35. Galloway AT, Lee Y \& Birch LL (2003) Predictors and consequences of food neophobia and pickiness in young girls. J Am Diet Assoc 103, 692-698.

36. Schagen S, Blenkinsop S, Schagen I, Scott E, Teeman D, White G, Ransley J, Cade J \& Greenwood D (2005) Evaluation of the School Fruit and Vegetable Pilot Scheme. Final Report, p. 59. London: Big Lottery Fund.

37. Wells L \& Nelson M (2005) The National School Fruit Scheme produces short-term, but not longer-term increases in fruit consumption in primary school children. BrJ Nutr 93, 537-542.

38. Reinaerts E, de Nooijer J, Candel M \& de Vries N (2007) Explaining school children's fruit and vegetable consumption: the contributions of availability, accessibility, exposure, parental consumption and habit in addition to psychosocial factors. Appetite 48, 248-258.

39. Bere E, Veierod MB, Bjelland M \& Klepp K-I (2006) Free school fruit - sustained effect 1 year later. Health Educ Res 21, 268-275.

40. Knai C, Pomerleau J, Lock K \& McKee M (2006) Getting children to eat more fruit and vegetables: a systematic review. Prev Med 42, 85-95. 
41. Bergstrand R, Vedin A, Wilhelmsson C \& Wilhelmsen L (1983) Bias due to non-participation and heterogeneous sub-groups in population surveys. J Chronic Dis 36, 725-728.

42. Bere E \& Klepp KI (2004) Correlates of fruit and vegetable intakes among Norwegian schoolchildren: parental and self-reports. Public Health Nutr 7, 991-998.

43. Tak NI, te Velde SJ, de Vries JH \& Brug J (2006) Parent and child reports of fruit and vegetable intakes and related family environmental factors show low levels of agreement. J Hum Nutr Diet 19, $275-285$.

44. Linneman C, Hessler K, Nanney S, Steger-May K, Huynh A \& Haire-Joshu D (2004) Parents are accurate reporters of their preschoolers' fruit and vegetable consumption under limited conditions. J Nutr Educ Behav 36, 305-308. 